\title{
Sustainable Workshops for Education Leaders for Applying Gained Knowledge
}

\author{
Jehan A Alandejani, \\ Northern Boarder University, \\ Arar, Saudi Arabia
}

Received: July 21, 2021. Revised: September 25, 2021. Accepted: October 6, 2021. Published: October 20, 2021.

\begin{abstract}
Workshops are very useful tools that allow participants to gain new knowledge and to promote selfdevelopment. However, most workshops tend to be presented in a way that isolates the workshop and the material being discussed and be more like a lecture than a workshop. The aim of this qualitative study was to learn more about how to design effective workshops for leaders. Saudi Arabia has set a clear vision for $\mathbf{2 0 3 0}$ to change in education and learning. Simultaneously, the country seeks to increase the female workforce by $8 \%$. To bridge the gap between work-shops and workshop efficacy and come closer to the Vision 2030's objectives. This study showed how trainers could re-design workshops to be more productive and meaningful. This qualitative study used a hermeneutic phenomenological research approach. Purposive sampling of 36 educational leaders from different departments. Two theories provided a rich foundation and framework for this qualitative study: social constructivist and transformational learning. This qualitative study revealed themes; the implementation of different learning strategies, use of reflection, and the assurance of a safe learning environment. Based on emerged themes and subthemes, tips that workshop professional developers should incorporate when planning and giving a workshop where extracted. The study shed some light on how trainers can transfer the core component in learning that relates to both process and outcome.
\end{abstract}

Keywords - sustainable learning, training, transfer of knowledge, workshops.

\section{INTRODUCTION}

$\mathrm{I}$ $\mathrm{N}$ professional fields, training becomes necessary for staff members at various levels to improve in the areas in which they are specialized [1]. Employees are expected to develop professional competencies and work practices to promote and sustain their development in values, behavior, and lifestyle [2]. Similarly, leaders are expected to develop in their leadership by learning and in practicing new leadership skills, creating and promoting innovative learning work environments, and leading effectively [3].

By 2030, Saudi Arabia aims to have five universities among the top 200 universities in international rankings. To accomplish this, Saudi Arabia must close the gap between higher education and job requirements and increase women's participation in the workforce by $8 \%$ and overall women's engagement in leadership positions [4]. To achieve such lofty goals, Saudi Arabia must move at a rapid pace towards the advancement of women into the workforce and provide opportunities for women to excel just as swiftly.

\section{LITERATURE REVIEW}

The idea of "workshops," offers a workable pedagogical method, one that provides the space and time participants need to discuss issues and challenges, create new knowledge, and maximize performance.

Although coined to represent the idea of working together in industry and manufacturing in Europe's eighteenth century, "workshop" as a concept is some-what immemorial and has become more generic than specific [5]. Workshops specifically provide an opportunity for information exchange, focused discussion of challenging or controversial topics, and active participation in exploring issues and creating new knowledge [6]. It is one of the persuasive methods for engaging the productivity of individuals and communicating organizational goals [7]. If implemented effectively, workshops can help influence instructors positively [2]. Thus, the goal of workshops is to provide a space where participants can train and acquire new knowledge, skills, and behaviors emphasized in the training programs, then transfer that knowledge and apply it to day-to-day activities [8]. Moreover, workshops lend support to the development of professional identities and work competencies, helping participants access their working memory to help transform their knowledge into practice $[9 ; 3 ; 7]$.

However, because workshops are not always designed well, they become more like instructor-led lectures and frequently fall short of their learning and transferring potential. As indicated by Steinert 1992, poorly designed workshops often lack essential aspects like hands-on activities, knowledgesharing discussion and actively engaged participants. 
Participants can become passive and reticent. In sum, workshops designed in a lecture format are void of inquiry and interaction. Therefore, processional activities need to take into account interests and needs of participants and stake holders [10].

A critical concern with any training program or workshop is the success of transferring the learning to the job [24]. The transfer is the core component in learning that relates to both process and outcome [11]. Transfer of learning goes beyond doing what is already known; it is effectively applying knowledge and skills gained in training- both on and off the job [11]. Therefore, by employing specific strategies, trainers can gain sufficient opportunities to build on their initial learning and use the newly gained knowledge when needed [12].

However, many have reported that most participants are not able to transfer the new knowledge that they have obtained from the training sessions or work-shops to their daily lives [12]. Although the participants find information provided in sessions precious and beneficial, they are unlikely to implement learned knowledge to their daily lives. However, workshops are not specifically practical, planners do not pay much attention to critical issues that affect both the learner and the transfer of knowledge [13]. Additionally, workshops do not portray the real world nor do they contribute to achieve effectiveness for participants in their environment [13]. In workshops participants are both an immigrant and an immigrant. They temporarily leave one environment or social system and temporarily enter an-other. "Although a certain amount of environmental baggage always accompanies learners to workshops, removing them from their natural setting for the time of the program isolates them from distractions and day-to-day concerns and enables them to concentrate on the problem at hand" [13, p. 42].

Professional developers or trainers may want to keep in perspective the transfer of knowledge when planning for the content and design of workshops. They also may need to think of ways and ideas to help the participants benefit from the sessions and apply them to their professional and personal lives. The study examined how professional developers can create effective leadership workshops that will help bridge the gap between workshops and workshop efficacy and bring the country closer to the Vision 2030's objectives. The aim of this qualitative study was to learn more about how to design effective workshops for leaders. The re-search sought to further explore what trainers can do to help participants become fully engaged in their learning so that they may successfully transfer the information and apply daily what they have learned.

Two theories provided a rich foundation and framework for this qualitative study: social constructivist and transformational learning. The social constructivist theory is extracted from constructivism, which focuses on how people make sense of their experiences and engage socially in order to make meaning of their processes [14]. The theory is useful for understanding why and how individuals react to new applied knowledge. Individuals transform existing experiences and understandings by relating it to new knowledge, monitoring their understanding throughout the process [3]. Transformational learning theory presented by Mezirow 2000 focuses both on the individual and the social meaning and occurs when there is a change in one's behavior, attitude or perspective.

This qualitative study was to find recommendations and techniques that professional development programmers or trainers can use when writing or developing a workshop, especially for leaders. The benefit of the study is to help professional developers create effective leadership workshops and bridge the gap between theory and reality. The study focused on the participants' experiences to understand the phenomena. Therefore, the research sought to answer the following questions:

1. How can professional development planners make workshops more productive and help trainers transfer the knowledge and practices they learned to their field?

2. How can we make professional development for leaders more efficient?

\section{MATERIALS AND METHODS}

This qualitative study used a hermeneutic phenomenological research approach, which is driven by human experiences and their perceptions of situations, and how they view themselves and their experiences [15]. Participants were selected in a purposive manner 36 educational leaders from different departments within the Education system. Data were collected through two types of qualitative approaches: observation and focus group. The researcher, who is a university educator, collected the data. During the workshops, the researcher acted as a participant observer - attending the session as an observer, but at times participating in the session's activities, noting and recording reactions from the attendees, all while remaining cognizant of the participants' interactions, comments and exchanges. The researcher chose the role of participant observer to establish trust between the participants and the researcher. It also provided patterns of behavior and helped the researcher experience the unexpected and gain a better understanding of any phenomena [16].

After the program was completed; participants went back to their daily lives. Three months later, the participants were invited to participate in a focus group. Focus group interviews were used to collect more data and to allow participants to express their perspectives on a similar experience [16]. Journal and memos were used to monitor subjectivity, reflexivity, and self-reflection while ensuring the credibility of the study [16]. The interview consisted of four open-ended questions that were funneled from the most general to the most specific:

1. Now that three months have passed, how did the program help you?

2. How much did you transfer from the workshops to your work environment?

3. What were the most strategies that stood out to you that helped you transfer the knowledge?

4. Explain what worked for you during the program. 
Tables 1 and 2 below provide the participants' demographic. The leadership program, the condition under which participants were observed, was a three-day program with two different sessions each day. The sessions focused on leader-ship skills and theories. Instructors were all specialized within their field, and they were asked to keep the different learning and teaching styles in mind. Most importantly, instructors were asked to talk and discuss Saudi Arabia's Vision 2030 and how it relates to leadership sessions being presented. Before the beginning of the program participants were given assessment surveys to check their level of understanding of the topics within the leadership program. The assessment helped the participants understand where they stand and accept the change they need to reach. Also, to help the participants understand themselves and help them benefit and transfer new knowledge [17].

Table 1. Participants' Years of Experience

\begin{tabular}{|c|c|}
\hline Years of Experience & Number of participants \\
\hline Less than One Year & 6 \\
\hline More than ten years & 11 \\
\hline From One to Three Years & 7 \\
\hline From Four to Six Years & 10 \\
\hline From Seven to Ten Years & 2 \\
\hline
\end{tabular}

Table 2. Participants' Position

\begin{tabular}{|c|c|}
\hline Position & Number of Participants \\
\hline Head Department & 10 \\
\hline School Principles & 18 \\
\hline Director & 8 \\
\hline
\end{tabular}

\section{ANALYSIS}

Thematic analysis was the approach used in a hermeneutic phenomenological study in order to investigate the experiences as it was lived rather than conceptualized [13]. According to Van Manen's model, themes are "experiential structures making up the experience", and it is necessary to search for the universal/general to the particular/specific experiences [15, $\mathrm{p}$. 123]. Van Manen's method was followed for approaching data. First, starting with the holistic approach by reading the data as a whole to capture the fundamental or significant meaning. Then, the selective reading approach to look for statements and phrases that reveal the phenomenon. Finally, the detailed reading approach to look at each sentence and line to see what can be further revealed about the phenomenon found earlier. The transcription margins were used to note the emerging themes and codes. Then the themes were separately written in chronological order and then identified and recorded to identify frequent links between the themes in a more analytical and theoretical way. While some themes were clustered, others were divided into sub-themes. After that, member check was done with the participants and educational director to ensure the validity of the themes, which was used to increase depth of understanding and to produce vibrant and creative results [15].

\section{RESULTS AND DISCUSSION}

Three major themes emerged from the data collected through the observations and the focus group: (a) the use of learning strategies, (b) the reflection, (c) the safe learning environment. Based on emerged themes and subthemes, tips that work-shop professional developers should incorporate when planning and giving a work-shop where extracted.

\section{A. The use of different learning strategies}

The major theme that stood out during the focus group and observations was the use of different learning styles. Transformational learning provided the frame-work for this theme. It helped participants understand and comprehend the content of the program through the use of different learning strategies. Trainers used a variety of teaching techniques and styles to help participants engage and comprehend the shared content. The different styles and techniques were cooperative learning, peer-tutoring, games, concept maps, storytelling, constructive feedback, and attentive listening.

Participants expressed gratitude towards the trainers' implementation of different learning styles within one session. Participant 6 expressed her feelings, saying: "it was absolutely wonderful and entertaining how some of the trainers moved from one activity to another, and each activity used a different learning strategy. I felt like child who was in science class and was seeing a volcano abrupt for the first time, and I was curious what we were going to learn next". From the observation notes: "the trainer starts off with an interactive game then displays an eye-catching video, and then shares a personal story that leads to humor.... participants are hooked for the first minute to the last and are willing to stay even though the session was over".

Therefore, trainers need to implement different learning styles in their training sessions because no two adult learners learn the same way [18]. Adult learners have different learning styles that are a result of their different learning preferences.

Furthermore, trainers need to use visual materials to reflect different types of people and provide an atmosphere of inclusiveness [20]. Also, changing the pace of the session always keeps participants more engaged and interested; it will add more excitement and will be unpredictable [21]. It will also help the trainer incorporate the different learning styles as changing from one pace to another.

\section{B. Reflection}

The Reflection was an unexpected theme, yet; appeared in three different sub-themes that emerged from the reflection theme. The social constructivist theory guided this theme. Participants' knowledge was constructed when they engaged socially in activities about shared problems or tasks. Through the social activity, the participants were able to share their experiences and stories and listen to other participants' experiences.

The first sub-theme was a reflection of their own experiences and stories. Re-flection is to review the important content and to become aware of their learning to be used in their professional and personal lives [21]. According to Gardner 2000, reflecting on one's experiences, participants 
will learn to go beyond the basic facts and deepen their understanding. It helped the participants better understand, link, and retain the information provided in the sessions [8]. Also, through reflection trainers were prompted to engage more actively with the material than they would actually do if they were left alone [22]. From the observation notes: "It was very obvious from the session how the participants were very eager to share their stories and experiences". According to participant 2, "we are always so busy in our daily lives that we forget to take time for ourselves and reflect on our experiences, but during the workshop they asked questions and gave us time to think and reflect".

The second sub-theme was listening to reflection of others; this gave them a sense of self belonging and connection to the information presented to them. Since workshops occur in the real world, participants were asked to bring real-world experiences and stories into the workshop. It was an effective way to allow participants to share their experiences and failures. It allowed learners to develop many different learning pathways that included pathways with themselves, with other participants, with the material, and with the trainer. The development of such pathways occurred because storytelling is an effective tool for finding commonalities and understanding differences that may occur in the learning experience [23]. Also stories serve an intrapersonal purpose by allowing one to make sense of the learning experience and to express emotions surrounding a learning event [24].

Moreover, stories can offer real and varied situations for participants to learn and provide repeated practice in everyday use [7]. Participant 11, enjoyed the experience of listening to stories, "what I loved the most was listening to others stories, I feel that it's what sticks the most and more natural to member because feelings are attached".

The third sub-theme was reflecting on the material and knowledge they learned. Participant 21, appreciated that trainers asked participants to choose one thing that they have gained or learned from the sessions and commit to applying it to their professional or personal life for the next week or month. She said, "this way, I came out with at least one professional or personal development I wanted to apply instantly." According to Vahastanen, Paloniemi, Hokka \& Etelapelt, unsuccessful development of shared work is when participants of a professional development program and their organization are not focused on enabling the participants' new knowledge [25].

\section{Safe Learning Environments}

This theme did not emerge as much as the other two, yet it is a success key for every professional development trainer. Participants expressed their feeling to-wards the importance of a safe environment and what it means to learn in an encouraging atmosphere. Participant number 26 said: "Because of the instructors' positive vibe and welcoming attitude, it was easy for me to take in all the information." While participant 12 said: "I felt at ease during the workshops, I did not feel the time pass by, and I wished that some of the workshops lasted longer. Be-cause the workshops were so motivational and positive, I actually applied some of the leadership skills, and I was monitoring which leadership style I used the most" From the observation notes: "participants all seem very engaged from their facial expressions I can see that they are enjoying. They are listening attentively, and they are participating willingly...the instructor started off with a welcoming activity that set the stage for the rest of the session".

The transformational theory also helped guide this theme. Through a safe and positive learning environment, participants were able to feel at ease and calm while learning. These positive feelings also helped the participants transfer their new knowledge back to work environments. Therefore, at the beginning of the work-shop, it is essential to maintain a positive environment that is inclusive and welcoming yet exciting and challenging [22]. Also, it is very crucial to provide a positive atmosphere that contains mutual respect for racial, cultural, socioeconomic, and religious differences. Building a positive attitude from the beginning will help trainers display and model respect for participants and recognize participants as unique individuals [26]. A positive environment enables participants to feel at ease to discuss and challenge ideas [22].

Ten practical tips were taken from this study that can give useful guidelines for trainers to effectively convey new knowledge to participants in a sustainable way. These tips will eventually help the learners acquire the knowledge and transfer it to their environment. These tips are:

1) Create a Positive Learning Environment attitude from the beginning.

2) Vary the learning styles in the workshop.

3) Modify the pace of the session.

4) Have participants share their experiences and stories.

5) Use Concept Maps to summarize contents.

6) Encourage participants to reflect on their learning experiences.

7) Incorporate Peer-tutoring into the activities.

8) Distribute Useful Handouts and send them electronically.

9) Have participants commit to one new thing that they will use.

10) Try to have a Follow-up session.

\section{CONCLUSION}

In conclusion, workshops are valuable educational formats for transmitting information and promoting acquisition skills. They have become a vital aspect of our professional lives. We depend on them to help adults learn what they need to know to help them in their professional and personal lives. However, they are use-less if the knowledge provided in the sessions does not get transferred to the participants' environment.

The study examined how professional developers can create effective leader-ship workshops that will help bridge the gap between workshops and workshop efficacy and bring the country closer to the Vision 2030's objectives. Also, the study shed some light on how trainers can transfer the core component in learning that relates to both process and outcome. By allowing adults to bring their experiences, we 
allowed them to bring a wealth of knowledge and skills into the learning environment. Also, this will lead to a successful implementation that changes the participants' attitudes and believes.

The transformational learning theory unveiled some of the constant factors. It explained how participants' transformational learning occurred when a safe environment was provided for participants. Also, it helped the researcher understand the complexity and multicity of reflection and its power to assist participants in transferring the knowledge and applying it to their professional and personal lives. Moreover, the social constructivist theory helped guide the participants to under-stand the shared content when they were able to reflect on their experiences and listen to other participants reflect on their experiences'. For further studies, mixed method research can be conducted to better understand the complexity of women's educational leadership in Saudi Arabia and how to make workshops more efficient and implementable.

\section{References}

[1] K.Vahastanen, S. Paloniemi, P. Hokka, P. and A. Etelapelto, Agentic perspectives on frosting work-related learning. Studies in Continuing Education. 201239 (3): 251-267.

[2] Collén K. Education for a sustainable future? Students' experiences of workshops on ethical dilemmas. Social work education. 2019 Jan 2;38(1):119-28.

[3] Yurtseven Yilmaz, Hatice, and Sedat Sever. "A Professional Development Analysis for Turkish Language Teachers: What Did They Expect? What Have They Found?." Journal of Pedagogical Research 5.1 (2021): 88113.

[4] Y. Steinert, Twelve tips for conducting effective workshops. Medical Teacher. 1992 Jan 1;14(2-3):127-31.

[5] Fleming, The workshop through new eyes. New Directions for Adult and Continuing Education. 1997 Dec;1997(76):95-8.

[6] Saudi Vision 2030. Retrieved from https://vision2030.gov.sa/en

[7] Razak, Wan Maziah Wan Ab, et al. "Relationship between Methods of Training, Trainer and Management Support towards Effective Training." (2021).

[8] B. Avalos, Teacher professional development in teaching and teacher education over ten years. Teaching and teacher education. 2011 Jan 1;27(1):10-20.

[9] Y. Ryan, Workshops elevate tech conferences. Electronic Engineering Times; 1998.

[10]Razak, Wan Maziah Wan Ab, et al. "Relationship between Methods of Training, Trainer and Management Support towards Effective Training." (2021).

[11]L. McDonald, S. Leberman and S. Doyle, The transfer of learning: Participants' perspectives of adult education and training. Gower Publishing, Ltd.; 2012 Oct 1.

[12]B. Stone, Transfer of learning: Implications for professional development. University of Northern Colorado; 2002.
[13] J, Johnson- Bailey, and RM. Cervero, Negotiating power dynamics in workshops. New directions for adult and continuing education. 1997 Dec;1997(76):41-50.

[14] L. McDonald, S. Leberman and S. Doyle, The transfer of learning: Participants' perspectives of adult education and training. Gower Publishing, Ltd.; 2012 Oct 1.

[15]D. Langdridge, Phenomenological psychology: Theory, research and method. Pearson education; 2007.

[16]C. Glesne, Becoming qualitative researchers: An introduction. Pearson. One Lake Street, Upper Saddle River, New Jersey 07458; 2016.

[17]TR. Guskey, Professional development and teacher change. Teachers and teaching. 2002 Aug 1;8(3):381-91.

[18] A. Honigsfeld, and R. Dunn, Learning-Style Characteristics of Adult Learners. Delta Kappa Gamma Bulletin. 2006 Jan 1;72(2).

[19] J, Johnson- Bailey, and RM. Cervero, Negotiating power dynamics in workshops. New directions for adult and continuing education. 1997 Dec;1997(76):41-50.

[20]Y. Steinert, Twelve tips for conducting effective workshops. Medical Teacher. 1992 Jan 1;14(2-3):127-31.

[21]D. Boyd, Effective teaching in accelerated learning programs. Adult Learning. 2004 Jan;15(1-2):40-3.

[22] Cy. Tseng, "Portraits of three teachers: factors that influence transfer of learning." (2006).

[23] SE. Butcher, Narrative as a teaching strategy. Journal of Correctional Education. 2006 Sep 1:195-208.

[24] J. McDrury and M. Alterio, Achieving reflective learning using storytelling pathways. Innovations in education and teaching international. 2001 Jan 1;38(1):63-73.

[25] Vahastanen, K., S. Paloniemi, P. Hokka, and A. Etelapelto. 2017. Agentic perspectives on frosting workrelated learning. Studies in Continuing Education 39 (3): 251-267.

[26] MW. Galbraith, Adult learning methods: A guide for effective instruction. Krieger Publishing Company, Krieger Drive, Malabar, FL 32950; 1998.

\section{Creative Commons Attribution License $\mathbf{4 . 0}$ (Attribution 4.0 International, CC BY 4.0)}

This article is published under the terms of the Creative Commons Attribution License 4.0

https://creativecommons.org/licenses/by/4.0/deed.en_US 